www.jmscr.igmpublication.org

Impact Factor (SJIF): 6.379

Index Copernicus Value: 71.58

ISSN (e)-2347-176x ISSN (p) 2455-0450

crossref DOI: https://dx.doi.org/10.18535/jmscr/v6i6.101

Journal Of Medical Science And Clinical Research

IGM Publication

An Official Publication of IGM Publication

\title{
Role of Mean Platelet Volume in Diagnosing Severity of Preeclampsia
}

\author{
Authors \\ Dr Priya Vijaykumar Gameti ${ }^{1}$, Dr Anisha Rajani ${ }^{2}$, Dr Mala Jain ${ }^{3}$ \\ ${ }^{1,2}$ Resident, Department of Pathology, Government Medical College, Surat, Gujarat, India \\ ${ }^{3}$ Resident, Department of Pathology, Government Medical College, Surat, Gujarat, India \\ Corresponding Author \\ Dr Priya Vijaykumar Gameti \\ Resident, Department of Pathology, Government Medical College, Surat, Gujarat, India
}

\begin{abstract}
Pregnancy induced hypertension (PIH) is the most common disorder of pregnancy affecting approximately 10-17\% of pregnancies and is a significant cause of maternal and fetal morbidity and mortality globally. The incidence of PIH in India ranges from 5\% to 15\%. Profound changes in the coagulation and fibrinolytic system occur during normal pregnancy causing a hypercoagulable state. Recent studies suggest that platelet parameters like platelet indices are markers of platelet activation and are rapid, cheap, most simple and cost effective method for prediction of PIH, way before the appearance of derangements in PT, APTT, TT values. Hence In our study we aimed to investigate the association between severity of preeclampsia and mean platelet volume. In this study MPV was found to be valuable in cases of multigravida subgroup. These indices gives proof of the role of platelet indices in diagnosing severity of preeclampsia and that the peripheral smear alone is not helpful and that these are simple,easy, rapid and cheap method to incorporate platelet indices in diagnosing preeclampsia.
\end{abstract}

Keywords: pregnancy, preeclampsia, Mean platelet volume, platelet.

\section{Introduction}

Pregnancy induced hypertension (PIH) is the most common disorder of pregnancy affecting approximately $10-17 \%$ of pregnancies and is a significant cause of maternal and fetal morbidity and mortality globally ${ }^{[1,2]}$. The incidence of PIH in India ranges from $5 \%$ to $15 \%^{[2,3]}$. Preeclampsia is defined as a multisystem disorder occurring in pregnancy and the puerperium which is characterized by development of hypertension of $140 / 90 \mathrm{mmHg}$ and above after the 20th week in a previously normotensive patient ${ }^{[4,5]}$. Preeclampsia can lead to two life threatening complications, eclampsia and HELLP syndrome ${ }^{[6]}$. The majority of patients remains in mild to moderate group and does not have any major obstetric problems. However, in a certain proportion of patients, the risk to the mother can be significant ${ }^{[1]}$. Profound changes in the coagulation and fibrinolytic system occur during normal pregnancy causing a hypercoagulable state ${ }^{[4,7,8]}$. Out of all the haematological abnormalities that occur in $\mathrm{PIH}$, thrombocytopenia is the most common seen to occur in $11 \%$ to $29 \%$ of patients ${ }^{[7,8]}$. These pregnancies also are associated with qualitative changes suggesting increased platelet production and destruction. There is a shortened platelet life span, increased numbers of megakaryocytes in the bone marrow, and an increased number of immature platelets seen in the 
peripheral blood smear ${ }^{[4,9,10]}$. Recent studies suggest that platelet parameters like platelet indices are markers of platelet activation and are rapid, cheap, most simple and cost effective method for prediction of $\mathrm{PIH}$, way before the appearance of derangements in PT, APTT, TT values ${ }^{[4,11,12]}$. Hence In our study we aimed to investigate the association between severity of preeclampsia and mean platelet volume (MPV).

\section{Material and Methods}

$>$ Study Setting: The present study was conducted in the Department of Pathology, Government Medical College associated with Tertiary care Hospital from December 2015 to August 2017.

$>$ Study Design: This study is a case control study looking at the platelet parameters in normal pregnant women as control and eclamptic pregnant women as study groups.

$>$ Study Site and Subjects

- Inclusion Criteria: The sample population consisted of, normal pregnant, and eclamptic pregnant females. Eclamptic pregnant females were defined as women with pregnancy induced hypertension with convulsion that cannot be attributed to another cause. Inclusion criteria for placement in the study group of eclamptic females were indoor patients coming in department of obstetrics and gynecology and clinically diagnosed cases of severe preeclampsia/eclampsia between second and third trimester between age group 18-40 years. Normotensive pregnant ladies between second and third trimester between 18-40years were taken as control.

- Exclusion criteria for this group were females patients who received recent blood transfusion.

> Sample size: Control-80 normotensive pregnant women

Study- 80 patients of eclampsia

Equipment and Instruments: The laboratory analysis was performed at the Hematology and clinical pathology laboratory of Department of pathology. An automated cell counter (Micros 60 haematology analyzer) was used to perform the complete blood count

- Data Analysis

All data was entered in excel sheet and master chart was prepared. All data entered was processed further and the statistical analysis performed on the entire sample used were mean, standard deviation, independent $t$ test.

This study has been approved by Institutional ethical committee.

\section{Observation}

Table 1: Distribution of Mean Platelet Volume (MPV) in Study and Control based on parity

\begin{tabular}{|c|c|c|c|c|}
\hline & \multicolumn{2}{|c|}{ Study (mean platelet volume in $\mathrm{fl}$ ) } & \multicolumn{2}{|c|}{ Control (mean platelet volume in $\mathrm{fl}$ ) } \\
\hline & PRIMI & MULTI & PRIMI & MULTI \\
\hline \multirow{2}{*}{ Mean } & 8.32 & 8.54 & 7.76 & 7.96 \\
\hline & \multicolumn{2}{|c|}{8.43} & \multicolumn{2}{|c|}{7.86} \\
\hline Standard Deviation & 1.19 & 1.36 & 1.08 & 1.15 \\
\hline Range & $5.9-11$ & $6.3-11.6$ & $5.7-10.5$ & $6.6-10.6$ \\
\hline P Value & 0.07 & 0.03 & & \\
\hline Significance & Not Significant & Significant & & \\
\hline
\end{tabular}

Table 2: Comparison of Mean Platelet Volume in Different studies

\begin{tabular}{|l|c|c|}
\hline Authors & Study (fl) & Control (fl) \\
\hline Amita et al & 9.60 & 8.89 \\
\hline Bhavana et al & 11.37 & 10.07 \\
\hline Vamseedhar et al & 11 & 8.63 \\
\hline Rabia et al & 10.49 & 8.42 \\
\hline Present study & 8.43 & 7.86 \\
\hline
\end{tabular}




\section{Discussion}

Few studies have been done regarding the feasibility of using MPV as markers in preeclampsia and eclampsia and have shown variable results. They have shown that there is macrothrombocytosis and increase in mean platelet volume in patients with moderate or severe hypertension in pregnancy ${ }^{[13,14]}$.Whereas another study showed that there was no change in the mean platelet volume in patients with mild to moderate hypertension ${ }^{[15]}$.

In present study we found mild increase in MPV values from normotensive pregnant women to eclampsia patients which correlated with other studies. In our study MPV is $8.43 \mathrm{fl}$ in eclampsia and $7.86 \mathrm{fl}$ in control group which is comparable with Amita et al who observed MPV of $9.60 \mathrm{fl}$ in study group and $8.89 \mathrm{fl}$ in control group ${ }^{[16]}$. Bhavana et al also observed the value of MPV as $11.37 \mathrm{fl}$ in eclampsia and $10.07 \mathrm{fl}$ in control .The higher values of MPV in Bhavana et al are not comparable to present study yet even though in present study MPV was within normal range the increase in MPV in eclamptic patients in comparison to normotensive patients was comparable to Bhavana et al ${ }^{[17]}$. Vamseedhar et al also reported MPV of $11 \mathrm{fl}$ in eclamptic patients and $8.63 \mathrm{fl}$ in control group and another study by Rabia et al reported the value of MPV as $10.49 \mathrm{fl}$ in eclampsia and $8.42 \mathrm{fl}$ in control group which are comparable to present study as the values are not significantly high and within normal range ${ }^{[18,19]}$. The $\mathrm{p}$ value in the present study was found to be insignificant when compared primigravida of study and control group but found to be significant comparing multigravida in study and control group suggesting there is no significant increase in MPV in primipara with increasing severity of preeclampsia but there is significant increase in MPV in cases of multipara with increasing severity of preeclampsia. Though several studies demonstrate direct relationship between MPV and preeclampsia severity our findings correlated with these studies in multipara subgroup only. This emphasizes that MPV has some role in pathogenesis of the disease .Due to increased consumption of platelets, bone marrow produces and release large platelets leading to increase MPV in preeclampsia. So any increase in MPV may be considered as a caution and patients can be monitored more carefully to avoid adverse outcome hence further studies are necessary to explore the usefulness of MPV in Preclampsia ${ }^{[20]}$. However literature reveals conflicting results regarding the relation between MPV and preeclampsia and there are studies which demonstrate increase in MPV even in healthy individuals ${ }^{[21]}$.In the present study MPV was proportionally higher in eclampsia as compared to normal pregnant females but the difference was not statistically significant. Amita et al also did not find any significant difference in the MPV between preeclampsia and normal pregnant group ${ }^{[16]}$. Vamseedhar et al and Bhavana et al in their study described MPV as a good marker of platelet dysfunction in preeclampsia. Similar findings were observed by Rabia et al. ${ }^{[17,18,19]}$. Recent studies demonstrate by Altibas et al observed that MPV is not a significant predictor of preeclampsia severity $^{[22]}$. Kashanian et al also observed that MPV changes did not predict preeclampsia or preterm labour and Cyehan et al did not observed any significant difference in the MPV [23,24]. This confusing behavior of MPV in various studies may be explained by the differences in equipment and method of automated cell counter ${ }^{[38]}$.Moreover MPV measurement should ideally be done soon after taking blood sample ${ }^{[18]}$.

\section{Conclusions}

Simple and easy procedure - Estimation of platelet count\& platelet indices are simple and routine tests, which can be easily estimated by automated hematology analyzer and hence can be used as an early and simple procedure in the assessment of severity of preeclampsia and prevent progression to complications. Platelet volume indices (PVIs) are a group of parameters which are inexpensive to measure and are derived from routine blood counts. Clinically platelet indices can be useful screening test in diagnosing severity of preeclampsia. These indices gives proof of the role of platelet indices in diagnosing severity of preeclampsia and that the peripheral smear alone is not helpful. However 
further large studies are required to generalize the findings for the population.

\section{Acknowledgement}

I would like to thank my faculty members, my seniors and juniors for their special and valuable inputs in our study.

\section{References}

1. Jyothi Shetty1, Sudha Rao2, M H Kulkarni2; Hematological changes in pregnancy-induced hypertension international journal of scientific study | august 2016 | vol 4 | issue 5

2. Feroza Sultana ${ }^{1}$, Raja Parthiban ${ }^{2}$, Shameem Shariff $^{3}$; Thrombocytopenia in pregnancy induced hypertension;Journal of Medical Sciences And Health/May-Aug 2015/volume 1/issue 2

3. Anand S, Kirshnanand. Perinatal outcome in growth retarded babies born to normotensive and hypertensive mothers: A prospective study. People's J Sci Res 2012;5:24-8.

4. Sameer MA, Meshram DP, Deshpande SA, Sadhu D, Pandit S.;Role of platelet count as important prognostic marker in pregnancy induced hypertension.; IOSR J Dent Med Sci2014;13:39-43.

5. Sibai. B.M. Hypertension in pregnancy. Clinical Obstet Gynecol, 1999:421-436.

6. Nobis PN1, Hajong A1.Eclampsia in India Through the Decades.j obstet gynecol india 2016 Oct;66(Suppl 1):172-6. doi: 10.1007/s13224-015-0807-5. Epub 2016 Jan 8.

7. Gibson G, Hunter D, Neame PB, Kelton JG. Thrombocytopenia in pre-eclampsia and eclampsia. Semin Thromb Hemost. 1982;8:234-247.

8. Pritchard JA, Cunningham FG, Mason RA. Coagulation changes in eclampsia: their frequency and pathogenesis. Am J Obstet Gynecol. 1976;8:855-864.

9. Burrows RF, Hunter DJS, Andrew M, Kelton JG. A prospective study investigating the mechanism of thrombocytopenia in preeclampsia. Obstet Gynecol. 1987;70:334338.

10. Saleh AA, Bottoms SF, Welch RA, Ali AM, Mariona FG, Mammen EF Preeclampsia, delivery and the hemostatic system. Am J Obstet Gynecol. 1987;1 57:331-336.

11. Mohapatra S, Pradhan BB, Satpathy UK, Mohanty A, Pattnaik JR. Platelet estimation: Its prognostic value in pregnancy induced hypertension. ;Indian J Physiol Pharmacol 2007;51:160-4.

12. A. Karateke, R.K. Kurt, A. Baloglu Relation of platelet distribution width (PDW) and platelet crit (PCT) to preeclampsia Ginekol Pol., 86 (5) (2015), pp. 372-375

13. Singer CR, Walker JJ, Cameron A, Fraser C. Platelet studies in normal pregnancy and pregnancy-induced hypertension. Clin Lab Haematol. 1986; 8(1):27-32.

14. Walker JJ, Cameron AD, Bjornsson S, Singer CR, Fraser C. Can platelet volume predict progressive hypertensive disease in pregnancy.Am J Obstet Gynecol. 1989 Sep; 161(3):676-9.

15. Dogru Y H, Yucel N, Pelit CF, Bolat G (2011) The importance and evaluation of mean platelet volume on the severity of preeclampsia. Prenatal Journal 19:108-13.

16. Amita K1,*, Nithin Kumar H2, Shobha SN3, Vijay Shankar4; The Role Of Platelet Parameters As A Biomarker In The Diagnosis And In Predicting The Severity Of Preeclampsia ;Indian Journal of Pathology and Oncology, April-June 2015;2(2);57-60

17. Thakur Bhavana, Kulkarni Vishal, Thakur Prashant; Platelet Indices in Pregnancy Induced Hypertension;J Cont Med A Dent. September-December 2016;4(3):20-26.

18. Vamseedhar A, Srinivasa K, Santosh K Y, Suresh DR. (2011) Evaluation of platelet indices and platelet counts and their significance in pre-eclampsia and eclampsia. Int J Biol Med Res 2:425 - 28. 
19. Rabia Parveen Siddiqui, Kajal Chandrakar, Ruchi Varma, Shruti Shrivastava. "Study on Platelet Indices in Pregnancy Induced Hypertension". Journal of Evidence based Medicine and Healthcare; Volume 2, Issue 44, November 02, 2015; Page: 8035-8040, DOI: 10.18410/jebmh/2015/1079

20. Akhila N R*1, Lingaraj Jayalakshmi2 and Komala Devi S D3 Study of Mean Platelet Volume in Gestational Hypertension and Normal Pregnancy ; International Journal of Biomedical Research 2015; 6(06): 366-369.

21. Altinbas S, Togrul C, Orhan A, Yucel M, Danisman N (2012) Increased MPV is not a significant predictor of preecalmpsia during pregnancy. J clin Lab Anal 26:403-06.

22. Kashanian M, Hajjaran M, Ghasemi A, Khatami E S (2012) Evaluation of the diagnostic value of the first and third trimester maternal mean platelet volume (mpv) for prediction of pre-eclampsia. Razi Journal of Medical Sciences 19;1-9.

23. Ceyhan T, Beyan C, Başer I, KaptanK, Güngör S and Ifran A (2006) the effect of pre-eclampsia on complete blood count, platelet count and mean platelet volume. Annals of Hematology 85:320-22.

24. Vagdatli E, Gounari E, Lazaridou E, KatsibourliaE, Tsikopoulou F, and Labrianou I (2010) Platelet distribution width: a simple, practical and specific marker of activation of coagulation. Hippokratia 14:28-32. 